\title{
Offensive but not so offensive: Fostering Ethical and Socially Responsible Marketing in Undergraduate Marketing Students.
}

\author{
Emmanuel Mogaji \\ University of Greenwich, London, UK \\ e.o.mogaji@greenwich.ac.uk
}

\begin{abstract}
Advertising that pushes the boundaries can sometimes be negatively received, some of these advertisements were reported to the regulator of advertising in the UK while Companies has had to apologise for their advertisements. The systemic diversity problem within the advertising industry is also acknowledged wondering if the industry is diverse enough to produce an advertisement that can appeal to a diverse audience. With this background, this paper presents a teaching innovation with the aim of addressing students' understanding of creative marketing campaign in a multicultural society through the integration of advertising practises codes, $A S A$ rulings and secondary research into the public perception of advertisement. The project is divided into five main parts and takes place over a three-week period. Students are expected to work with advertisements that vert reported being offensive, research public's attitude towards them and present their justifications for either agreeing or disagreeing with the rulings. This project allows a better understanding of the creative challenges in developing an ethical and socially responsible marketing campaign; finding a balance between creativity and freedom of expression, they can better internalise the integrative nature of the marketing concept, a valuable skill for the industry.
\end{abstract}

Keywords: Ethics, ASA, Socially Responsible Marketing, Marketing, Undergraduate student, Teaching innovation

\section{Introduction}

The UK is considered one of the most diverse countries in Europe, home to individuals of different cultures, races and religions, and these diversified market groups have also compelled advertisers to pay increased attention to the targeting of consumers using forms of marketing communication to which they can relate (Mogaji, 2015). Pepsi had to pull their advert with Kendall Jenner after a huge backlash because it was deemed exploitive of the Black Lives Matter campaign. After being accused of racism in a campaign promoting body lotion, Dove apologised for an ad showing a black woman turning into a white one. Threats were also made to boycott Tesco after a Muslim family featured in their Christmas advertisement, and H\&M issued an 'unequivocal apology' for featuring a black child posing in a 'coolest monkey' hoodie. These examples clearly 
illustrate the challenges of developing a marketing campaign within a multicultural society.

In addition, a systemic diversity problem has also been acknowledged in the advertising industry (Rahim, 2017). Advertising agencies are often questioned about whether they are diverse enough to produce advertisements that can appeal to a diverse audience, as a truly diverse workplace is the societal equivalent of a meaningful brainstorm (Blair, 2017). The industry's lack of black and minority ethnic employees is also an issue. Shearman (2017) reported findings from the Institute of Practitioners in Advertising (IPA) which found that $13 \%$ of agency staff were from BAME backgrounds.

Considering these issues, this paper presents a teaching innovation to improve students' understanding of creative designs in marketing communication as they prepare for work in the industry. Irrespective of their race or gender, they are well equipped and educated to deal with these challenges, make contributions towards creative designs and be better marketers. The innovation is intended to address students' understanding of creative marketing campaigns in a multicultural society through the application of integration of advertising practice codes, ASA rulings and secondary research into public perceptions of advertisements.

\section{The innovation}

In 2016, the ASA resolved over 29,000 complaints relating to approximately 16,000 advertisements, and 4,584 of these advertisements were either changed or removed because of the lodged complaints (ASA, 2017). Marketers want to make sure that they get their advertisements right. They want to avoid the need for public apologies and withdrawal of advertisements when they get it wrong. These are the concerns this teaching innovation aims to address.

In relation to the teaching of ethical and societal issues in marketing communications, advertising and promotion, the teaching innovation engages undergraduate marketing students to understand the UK advertising code of practice, discuss ASA findings on advertisements considered to be offensive and carry out secondary research to understand attitudes of members of the public towards advertisements (Figure 1), thereafter presenting their justifications for either agreeing or disagreeing with the ASA's rulings.

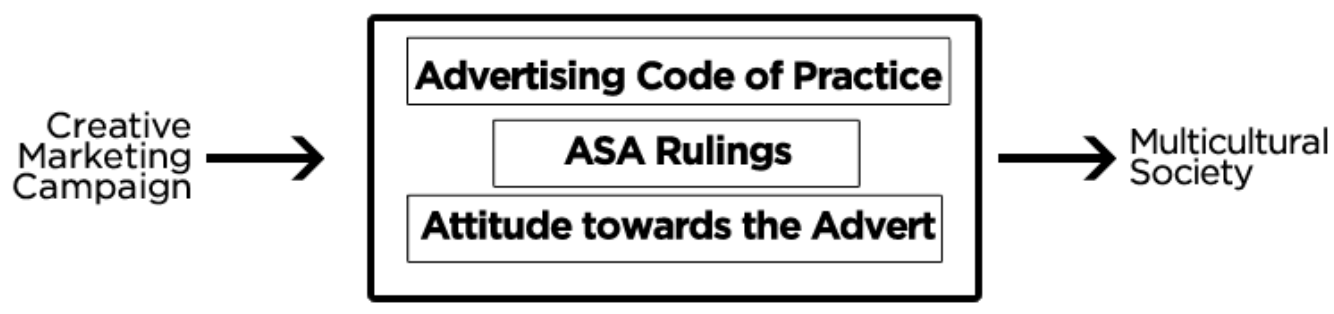

Figure 1: Teaching innovation with the three core background. 
For various reasons, this teaching innovation is considered novel, particularly as it involves studying advertisements that have been reported and investigated as offensive, and it brings an existing marketing campaign to the classroom to challenge students' ethical and professional stance. Rulings by the ASA are incorporated in the project, and this allows students to understand better the regulations involved in developing a marketing campaign. It is also based on real data from user-generated content on social media that is readily available public data and can be thematically analysed (Mogaji \& Farinloye, 2017) to better understand attitudes towards these advertisements.

This teaching innovation challenges students in different ways as they develop their critical approach to learning. Students are supported with lower-order thinking skills (i.e. remembering, understanding and applying) and higher-order thinking skills (i.e. analysing, evaluating and creating) (Bloom \& Krathwohl, 1956). This is a form of experiential learning that fosters active learning (Kolb \& Kolb, 2005) and effective knowledge acquisition (Hamer, 2000; Granitz \& Koering, 2011; Zarzosa \& Fischbach, 2017).

This teaching method is valuable as students develop an ability to understand ethical and societal issues in marketing strategies better. They therefore become more aware of what is socially acceptable. Students are better prepared for work in the advertising industry through enhancing their understanding of these multicultural issues. This helps them deal with ambiguity relating to ethical marketing campaigns (Loe \& Ferrell, 2001; Zarzosa \& Fischbach, 2017). It also benefits international students as they can transfer this knowledge to their own countries and explore the possibilities of adopting creative marketing strategies that are more culturally acceptable.

\section{Objectives}

At the end of this project, students are expected to be aware of their ethical and professional stance with regards to marketing campaigns that will help them internalise the integrative nature of the marketing concept, a valuable skill for the industry (Cowley, 2017; Evans, 2001).

Secondly, students will understand creative challenges in developing a marketing campaign that is not offensive or against societal norm, reflecting the diversified society and finding a balance between creativity and freedom of expression.

Thirdly, students will be able to share their thoughts and opinions regarding marketing campaigns, learning from each other and sharing ideas. As observed by Zarzosa and Fischbach (2017), a social constructivism learning approach is adopted here, and 'students construct knowledge for one another collaboratively through social interactions while the instructor plays a facilitator rather than instructive role' (p. 105).

Finally, students will be able to synthesise data from a range of sources such as the ASA rulings and user-generated comments to understand attitudes towards advertisements (Mogaji, 2016). The students will be able to present their arguments and rebuttals effectively, encouraging an ethical debate to strengthen their efficacy toward ethical decision making (Ferrell, 1996). 


\section{Outline}

The teaching innovation aims to get students engaged with real-life advertisements that have been considered offensive. However the ASA disagrees with these claims. Students are to familiarise themselves with the advertising code of practices, collect and analyse secondary data in the form of user-generated comments on social media to understand the general perception about the advertisement and after that present a report to justify their position that either agrees or disagrees with the ASA ruling.

This process is divided into five main parts and takes place over a three-week period as illustrated in Table 1. During the first week, the instructor gives an overview of the exercise, relating it to previous teachings on ethical and societal issues on marketing communications, advertising and promotion, as these concepts provide students with theoretical frameworks necessary to complete the project. The selected advertisements are shown during class, and an initial general discussion is held before the students are divided into five groups, and they examine one of the advertisements assigned to their group.

\begin{tabular}{|c|c|c|c|}
\hline \multirow{2}{*}{$\begin{array}{l}\text { Time } \\
\text { Frame }\end{array}$} & \multirow[t]{2}{*}{ Stages } & \multicolumn{2}{|l|}{ Obligation } \\
\hline & & Instructor & Students \\
\hline Week 1 & 1. Introduction & $\begin{array}{l}\text { - Give an overview and } \\
\text { introduce the exercise }\end{array}$ & $\begin{array}{l}\text { - Discuss the } \\
\text { advertisements in the } \\
\text { class } \\
\text { - Divide themselves into } \\
\text { group }\end{array}$ \\
\hline Week 2 & 2. Research & $\begin{array}{l}\text { - Assist with any } \\
\text { challenges as students } \\
\text { get on with their } \\
\text { research }\end{array}$ & $\begin{array}{l}\text { - Discuss any research } \\
\text { challenge. } \\
\text { - Continue group work - } \\
\text { use the Code of practice, } \\
\text { ASA rulings and } \\
\text { research into user- } \\
\text { generated contents on } \\
\text { social media } \\
\text { - Prepare for presentation } \\
\text { next week. }\end{array}$ \\
\hline \multirow[t]{3}{*}{ Week 3} & 3. Presentation & $\begin{array}{l}\text { - Chair the presentation } \\
\text { session }\end{array}$ & $\begin{array}{l}\text { - Present findings and } \\
\text { justifications. }\end{array}$ \\
\hline & 4. Feedback & $\begin{array}{l}\text { - Give Feedback after } \\
\text { presentation and } \\
\text { discussion }\end{array}$ & $\begin{array}{l}\text { - Discussion about the } \\
\text { group findings }\end{array}$ \\
\hline & 5. Reflection & $\begin{array}{l}\text { - Collects anonymous } \\
\text { reflective points of the } \\
\text { groups }\end{array}$ & - Reflection \\
\hline
\end{tabular}

Table 1: Project Timeframe and Procedures. 
The instructor provides the link to the advertisements, usually on YouTube, and students can watch them during class and in their study time. The instructor directs the students to the UK Code of Non-Broadcast Advertising, Sales Promotion and Direct Marketing that is written and maintained by the Committee of Advertising Practice (CAP), and the ASA websites where they can get the rulings of each of the advertisements.

Furthermore, the instructor provides information on researching user-generated comments on social media to gain insight into an attitude towards the selected advertisements. Over the second and third weeks, the students take responsibility for the exercise and continue their group research work using the ASA rulings and usergenerated content on social media. They can discuss any research challenges they may face, and the instructor will be able to provide guidance and assistance.

During the last week of the project, the students present their reports and there is a general discussion regarding the findings from all five working groups. The students can challenge their opinion compared to their initial views at the beginning of the project, and there is a reflection after the exercise where the instructor collects students' views to see how well they understood the exercise.

\section{Student Assessment}

Students are assessed on their ability to reflect on the advertisements, identify features that can be considered offensive; provision of an alternative creative idea and the presentation of their research findings to justify their decisions to either accept or reject the ASA rulings. After the group presentations, the students have an opportunity to reflect on their thoughts before and after the exercise, after reading the codebook, the ASA rulings and society's perception of the advertisements. The students are told to write a few words about what they have learnt and what challenges they experienced throughout the project. This exercise serves as feedback to the instructor and is also used to help evidence if the objectives of the project have been met. The students are more aware of what could be deemed as offensive and the thin line between abiding and breaching the advertising code.

\section{Challenges}

Even though the advertisements used in this project were ruled as not in breach of the advertising codes in the UK, the students are challenged to critically examine them in the context of ethical and societal standards. The instructor needs to provide background information on the exercise and advertisements to prepare the students. Some students may still be uncomfortable with the advertisements, and it is the instructor's responsibility to reassure them and respect their choice if they decide not to participate.

Issues like this can also be mitigated if the instructor ensures the students that the advertisements used for the exercise have not been banned or ruled against, even though the aim is to challenge them on ethical issues. Therefore, the instructor should avoid advertisements that have been banned and considered offensive to broadcast.

Sourcing the resources for the project is challenging, particularly locating the advertisements. YouTube is a useful source, and some of the advertisements can also be found on social media outlets such as Facebook and Vimeo. The rulings of the 
advertisements may not be available on the regulator's website, and the instructor can communicate with the body to obtain the official ruling; however, if this is not possible, press coverages of the rulings can be helpful.

\section{Adaptation}

Instructors in marketing strategy, advertising, ethical and societal issues can adapt this project to enhance the learning experience of their students. Guidance for implementing this teaching technique is provided as well.

The project could be further adapted by using advertisements that reflect different ethical or societal challenges, for example, the portrayal of women and children in advertisements or advertisements with sexual or alcohol content. These topics can also challenge the professional and ethical stance of the students as they strike a balance between creativity and acceptable societal norms.

This innovation employed user-generated content on social media to gain insight into attitudes towards the advertisements. Future adaptations of this project could use other data gathering methods such as street intercept where the advertisements are shown to a passer-by in print format or on the tablet to understand their views.

The innovation sets out to explore advertisements that are considered offensive and have been reported and investigated by the ASA. Subsequent adaptations could involve searching databases of other regulatory bodies such as the United States' Federal Trade Commission (FTC), the European Advertising Standards Alliance (EASA) or the Advertising Standards Bureau (ASB) of Australia to uncover other advertisements that challenge societal norms.

Regulatory bodies are required to rule against an advertisement while considering a balance between creativity and the advertisers' freedom of expression. Different regulatory bodies may have different rulings on the same advertisement, and that adds a further multi-cultural perspective to this innovation and also benefits international students because of the ethics that specifically apply to their own countries.

It is acknowledged there might be an ethical debate in class, for example, the instructor can show the most controversial advertisement and offers the students an opportunity to present their arguments and rebuttals regarding the ASA ruling. This allows the student to relate the ethical discussion to their own experiences (Zarzosa \& Fischbach, 2017) and their own professional expectations; this type of ethical debate has been identified to improve critical thinking skills of students.

\section{Conclusion}

In summary, this project has engaged students with ethical and societal issues associated with marketing, especially in a multicultural society. Students are exposed to advertisements that some individuals consider offensive, even though they were ruled as not in breach of the relevant codes and this brings a real-world marketing campaign experience to the classroom to challenge their ethical and professional stance. 
McAlister (2004) noted that business schools acknowledge the importance and their responsibility to train students to make ethical decisions, coupled with the fact that they are being prepared to work in a multicultural global market. Therefore, the students will be better equipped to work with ethical marketing issues, and that will strengthen their efficacy toward ethical decision making (Ferrell, 1996).

\section{References}

ASA. (2017). 2016's most complained about ads. Asa.org.uk. Retrieved 13 September 2017, from https://www.asa.org.uk/news/2016-s-most-complained-about-ads.html

Blair, A. (2017). Advertising's lack of diversity stifles creativity. The Guardian. Retrieved 30 December 2017, from https://www.theguardian.com/medianetwork/2016/apr/15/advertising-lack-of-diversity-stifles-creativity

Bloom, B. S., \& Krathwohl, D. R. (1956). Taxonomy of educational objectives: The classification of education goals, Handbook: Cognitive domain. London, England: Longman.

Cowley, S. W. (2017). The Buzzfeed Marketing Challenge: An Integrative Social Media Experience. Marketing Education Review, 27(2), 109-114.

Evans, J. R. (2001). The emerging role of the Internet in marketing education: From traditional teaching to technology-based education. Marketing Education Review, 11 (3), $1-14$.

Ferrell, L. K. (1996). Gray matters ethics training: An evaluation. (Doctoral dissertation), the University of Memphis, Memphis, TN.

Granitz, N., \& Koernig, S. K. (2011). Web 2.0 and marketing education: Explanations and experiential applications. Journal of Marketing Education, 33(1), 57-72.

Hamer, L. O. (2000). The additive effects of semistructured classroom activities on student learning: An application of classroom-based experiential learning techniques. Journal of Marketing Education, 22(1), 25-34.

Kolb, A. Y., \& Kolb, D. A. (2005). Learning styles and learning spaces: Enhancing experiential learning in higher education. Academy of Management Learning \& Education, 4(2), 193-212.

Loe, T. W., \& Ferrell, L. (2001). Teaching marketing ethics in the 21 st century. Marketing Education Review, 11(2), 1-15.

McAlister, D. T. (2004). Building ethical capacity in business schools. Marketing Education Review, 14(3), 55-62.

Mogaji, E., \& Farinloye, T. (2017). Attitude towards brands and advertisements: Qualitative and thematic analysis of social media data. In Rishi, B., \& Bandyopadhyay, S. (Eds.), Contemporary Issues in Social Media Marketing. Abingdon, Oxon: Routledge. 
Mogaji, E. (2016). This advert makes me cry: Disclosure of emotional response to advertisement on Facebook. Cogent Business \& Management, 3(1), Online Journal

Mogaji, E. (2015). Reflecting a diversified country: A content analysis of newspaper advertisements in Great Britain. Marketing Intelligence \& Planning, 33(6), 908-926.

Rahim, H. (2017). 'Diversity isn't just good for society - it's good for our business,' says Grey London chief. The Telegraph. Retrieved 30 December 2017, from http://www.telegraph.co.uk/connect/better-business/diversity-in-advertising-vitalfor-good-creative-ideas/

Shearman, S. (2017). Women in advertising: 'Diversity will make our industry more creative'. The Guardian. Retrieved 30 December 2017, from https://www.theguardian.com/media-network/2016/mar/08/international-womensday-diversity-advertising-industry-creative

Zarzosa, J., \& Fischbach, S. (2017). Native Advertising: Trickery or Technique? An Ethics Project and Debate. Marketing Education Review, 27(2), 104 - 108. 